\title{
Short communication: Repeatability of intravenous glucose tolerance test traits in young Holstein-Friesian cattle
}

\author{
L. Antonio González-Grajales, ${ }^{1 *}$ Laura Pieper, ${ }^{1,2}$ Stefan Görner, ${ }^{1}$ Philipp Görner, ${ }^{1}$ and Rudolf Staufenbiel ${ }^{1}$ \\ ${ }^{1}$ Ruminant and Swine Clinic, Free University of Berlin, 14163 Berlin, Germany \\ ${ }^{2}$ Institute for Veterinary Epidemiology and Biostatistics, Free University of Berlin, 14163 Berlin, Germany
}

\section{ABSTRACT}

Few studies have compared individual variability of an intravenous glucose tolerance test (ivGTT) obtained daily in young cattle. The objective of this study was to evaluate the repeatability of glucose traits and insulin responses derived from ivGTT during 3 consecutive days in Holstein-Friesian cattle (bulls: $\mathrm{n}=4$, steers: $\mathrm{n}$ $=3$, heifers: $\mathrm{n}=3$ ). Blood collections were performed from min 0 (basal concentrations) to min 63 (last measurement). Additional estimates included maximal concentration for glucose and insulin, glucose half-life time (GHLT), and glucose and insulin area under the curve. Glucose traits showed higher repeatability when compared with insulin responses. On average, the glucose trait and insulin response with the lowest coefficient of variation was GHLT $(0.7 \%)$ and insulin area under the curve $(21.3 \%)$, respectively. In addition, a general linear model with repeated measures was used to test for significant differences in glucose and insulin concentrations over time at different trial days. Both glucose and insulin concentrations were influenced by time point but not by trial day or time point $\times$ trial day. The results from this study showed that individual insulin responses were more variable than glucose traits. The high repeatability of GHLT evidenced the strict regulatory glucose disposal mechanisms occurring in young Holstein-Friesian cattle, whereas insulin responses showed high variability despite controlled management and nutritional practices.

Key words: coefficient of variation, glucose half-life time, insulin, intravenous glucose tolerance test

\section{Short Communication}

Monitoring glucose and insulin responses through an intravenous glucose tolerance test (ivGTT) is a valuable procedure to diagnose conditions affecting

Received August 29, 2018.

Accepted November 29, 2018.

*Corresponding author: leslieantonio.gonzalezgrajales@fu-berlin.de carbohydrate metabolism in domestic cattle (Opsomer et al., 1999; Binici et al., 2016). The ivGTT allows the quantification of blood glucose and insulin concentrations at specific time points once a glucose dose is administered intravenously. The values provide general information about some regulatory processes governing glucose uptake and turnover rates (Kaneko, 1997).

Recently, our research group identified glucose parameters (e.g., required time to decrease half of the glucose dose from bloodstream commonly known as glucose half-life time) derived from the ivGTT with high heritability in adolescent Holstein-Friesian bulls (Pieper et al., 2016). The heritability value for this glucose trait was 0.40 , which raises the possibility to examine associations between different glucose half-life time (GHLT) values and impaired metabolic responses in dairy cattle as a result of disturbances in energy balance during the prepartal period (McNeel et al., 2017). Therefore, test standardization is important to obtain repeatable and reliable data. We have reported about test standardization including fasting times (GonzálezGrajales et al., 2017), glucose dose (González-Grajales et al., 2018), and management and nutritional measures (Görner, 2011). However, test repeatability in young Holstein-Friesian cattle is unknown. The study hypothesis was that glucose traits and insulin responses derived from an ivGTT would be repeatable during 3 consecutive days under controlled feeding and management conditions.

Ten animals were purchased from a commercial dairy farm in Brandenburg, Germany. Holstein-Friesian bulls $(\mathrm{n}=4)$, steers $(\mathrm{n}=3)$, and heifers $(\mathrm{n}=3)$ were enrolled in the study. Age for bulls, steers, and heifers was $415(\mathrm{SD}=13), 439(\mathrm{SD}=49)$, and $448 \mathrm{~d}(\mathrm{SD}$ $=1$ ), respectively. Body weights for bulls, steers, and heifers were $495(\mathrm{SD}=21.7), 421(\mathrm{SD}=41.6)$, and 431 $\mathrm{kg}(\mathrm{SD}=21.8)$, respectively. Backfat thickness $($ BFT $)$ in bulls, steers, and heifers was $11.7(\mathrm{SD}=1.14)$, $10.6(\mathrm{SD}=2.0)$, and $18 \mathrm{~mm}(\mathrm{SD}=1.7)$, respectively. Backfat thickness was assessed according to Schröder and Staufenbiel (2006) using a portable ultrasound. Animals were housed in individual tiestalls with head- 
locks in the experimental facilities at the Ruminant and Swine Clinic, Free University of Berlin, Germany. A period of $8 \mathrm{wk}$ before the experiments was implemented to accustom the experimental animals to the housing facilities, nutritional diet, and daily routine practices.

Each individual was subjected to a total of 3 ivGTT conducted $24 \mathrm{~h}$ apart. All diagnostic procedures were performed by the same technician and approved by the Landesamt für Arbeitsschutz, Gesundheitsschutz und technische Sicherheit in Berlin, Germany, under protocol number G 0023/04. The diet contained $1 \mathrm{~kg}$ of hay, $0.1 \mathrm{~kg}$ of straw, and $1.5 \mathrm{~kg}$ of concentrate. Feed was administered 4 times per day (Supplemental Table S1; https://doi.org/10.3168/jds.2018-15617). Water was available at all times.

Animals were fasted for $12 \mathrm{~h}$ before each ivGTT. Glucose tolerance test was performed as described by Pieper et al., (2016). Briefly, an indwelling $14 \mathrm{G} \times 8$ $\mathrm{mL}$ cannula (Melsungen AG, Melsungen, Germany) was inserted in the jugular vein immediately after BW and BFT assessment to minimize interference of stress hormones with carbohydrate metabolism. A $40 \%$ glucose solution (B Braun Vet Care, Melsungen AG) at 1 $\mathrm{g} / \mathrm{kg} \mathrm{BW}{ }^{0.75}$ was administered i.v. Sampling was performed every 7 min until min 63 after glucose injection. Serum was recovered and stored at $-18^{\circ} \mathrm{C}$ until needed. The hexokinase method was used to determine serum glucose concentrations with the Gluco-quant Glucose/ HK Cobas test (Roche Diagnostics GmbH, Mannheim, Germany) according to the manufacturer's instructions. Minimal detectable concentrations for this method was at $0.11 \mathrm{mmol} / \mathrm{L}$. Glucose traits derived from the ivGTT included basal glucose concentration (G0), maximal glucose concentration (GMAX), glucose concentration at min 63 (G63), GHLT, and glucose area under the curve (GAUC). The last parameter was estimated using the trapezoid rule, whereas GHLT was calculated as described by Kaneko (1997) using the linear regression analysis of the natural logarithm of the glucose concentrations. Insulin concentrations were assessed by solid-phase RIA using a commercial kit (Radioimmuno-coat-A-count insulin, DPC Bierman GmbH, Bad Nauheim, Germany) following Kremer's (2008) indications. Analytical sensitivity was 1.2 $\mu \mathrm{IU} / \mathrm{mL}$. Insulin responses derived from the ivGTT included basal insulin concentration (Ins0), maximal insulin concentration (InsMAX), insulin concentration at min 63 (Ins63), and insulin area under the curve (InsAUC). Coefficients of variation (CV) for glucose traits and insulin responses were calculated by dividing the standard deviation by the mean using the program Microsoft Excel 2013 (Microsoft Corp., Redmond, WA). To determine whether trial day and time point $\times$ trial day influenced glucose and insulin responses, general linear model with repeated measures was employed using the program SPSS Statistic version 22 (IBM Deutschland GmbH, Ehningen, Germany) for Windows. Furthermore, to determine the effects of sex, age, and BFT on ivGTT traits and insulin, generalized linear-mixed models were employed and the results are shown in Supplemental Tables S2 and S3 (https:// doi.org/10.3168/jds.2018-15617). Descriptive statistics and CV for glucose traits and insulin responses are displayed in Tables 1 and 2, respectively.

The G0 and GMAX concentrations ranged from 4.39 to $5.25 \mathrm{mmol} / \mathrm{L}$ and 13.1 to $16.1 \mathrm{mmol} / \mathrm{L}$, respectively. The G63 varied from 6.60 to $7.88 \mathrm{mmol} / \mathrm{L}$. The GHLT ranged from 49.7 to $61.1 \mathrm{~min}$, whereas values for GAUC reached 525.9 to $611.9 \mathrm{mmol} / \mathrm{L} \times 63 \mathrm{~min}$. Insulin responses showed greater variation when compared with glucose traits. The Ins0 and InsMAX concentrations ranged from 8.70 to $13.9 \mu \mathrm{IU} / \mathrm{mL}$ and 40.2 to 145.4 $\mu \mathrm{IU} / \mathrm{mL}$, respectively. The Ins63 values varied from 17.6 to $53.8 \mu \mathrm{IU} / \mathrm{mL}$, whereas InsAUC values ranged between $1,545.1$ to $4,124.2 \mu \mathrm{IU} / \mathrm{mL} \times 63 \mathrm{~min}$. The glucose traits with the greatest and lowest $\mathrm{CV}$ were G63 $(3.7 \%)$ and GHLT $(0.7 \%)$, respectively (Table 1). Insulin responses exhibited higher $\mathrm{CV}$ values compared with CV obtained from glucose traits. The InsAUC had the lowest $\mathrm{CV}$ value (21.3\%), whereas Ins0 the greatest (34.4\%; Table 2).

Response curves for glucose and insulin during the ivGTT are presented in Figure 1. Trial day had no effect on glucose $(P=0.846)$ or insulin $(P=0.170)$ concentrations. Similarly, neither glucose $(P=0.773)$ nor insulin concentrations $(P=0.113)$ were affected by time point $\times$ trial day over time. Only time point influenced glucose and insulin concentrations $(P<$ 0.001). Glucose concentrations were very similar from time point 0 to min 63 among trial days (Figure 1A). In contrast, numerical increases on insulin maximal concentrations were observed at each trial day from time point 7 to time point 14 . Thereafter, insulin concentrations were proportionally decreasing depending on trial day until time point 28. Differences in insulin concentrations among trial days were small at subsequent time points (Figure 1B). Sex and BFT influenced GMAX and GAUC (Supplemental Table S2; https:// doi.org/10.3168/jds.2018-15617) with a lack of effects on insulin responses (Supplemental Table S3; https:// doi.org/10.3168/jds.2018-15617).

In this study, glucose and insulin responses were assessed daily over $3 \mathrm{~d}$ to determine individual repeatability, enrolling animals with similar age and BW to decrease the influence of these factors on the responses. Differences attributed to sex and BFT must be care- 

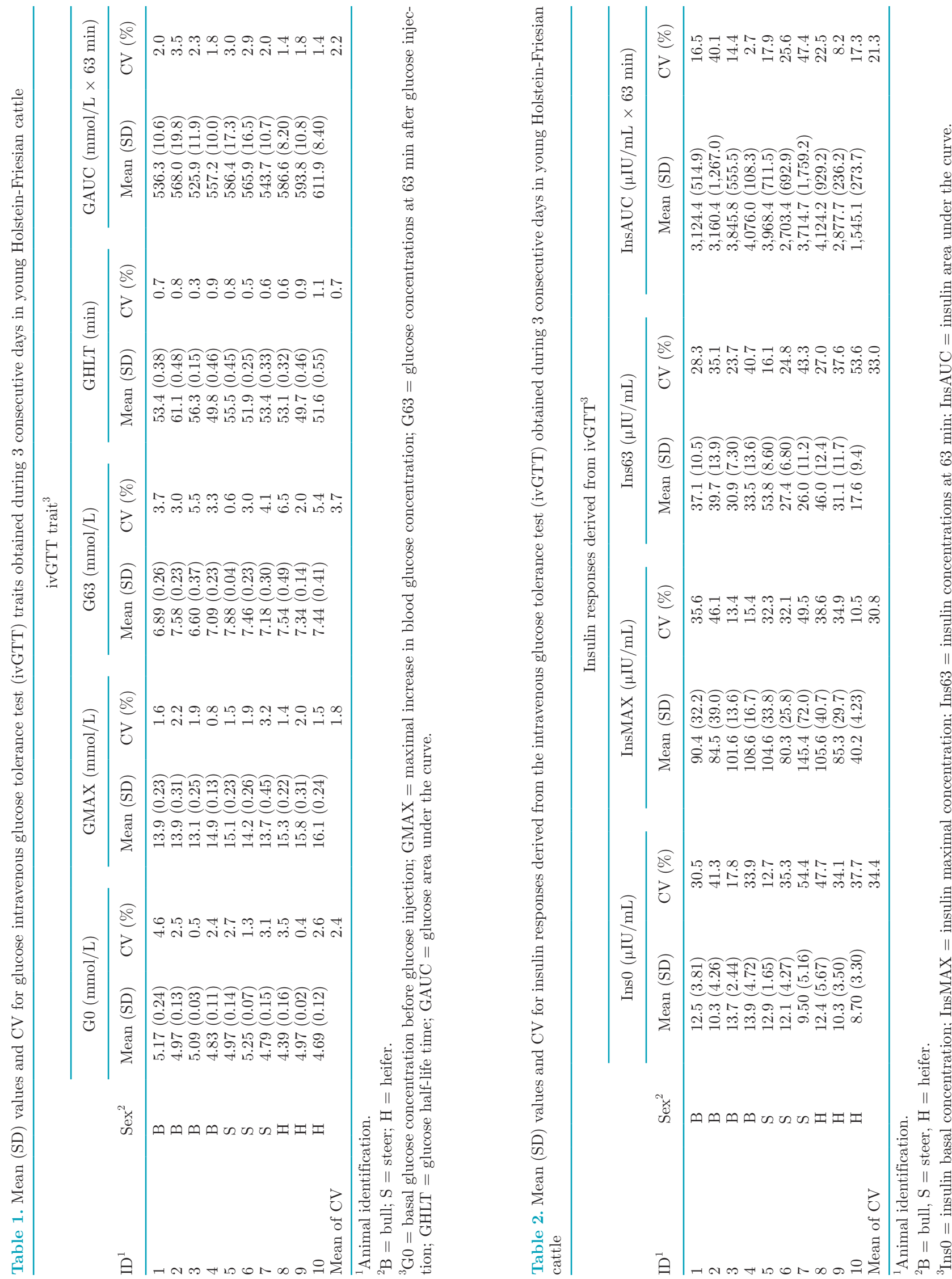

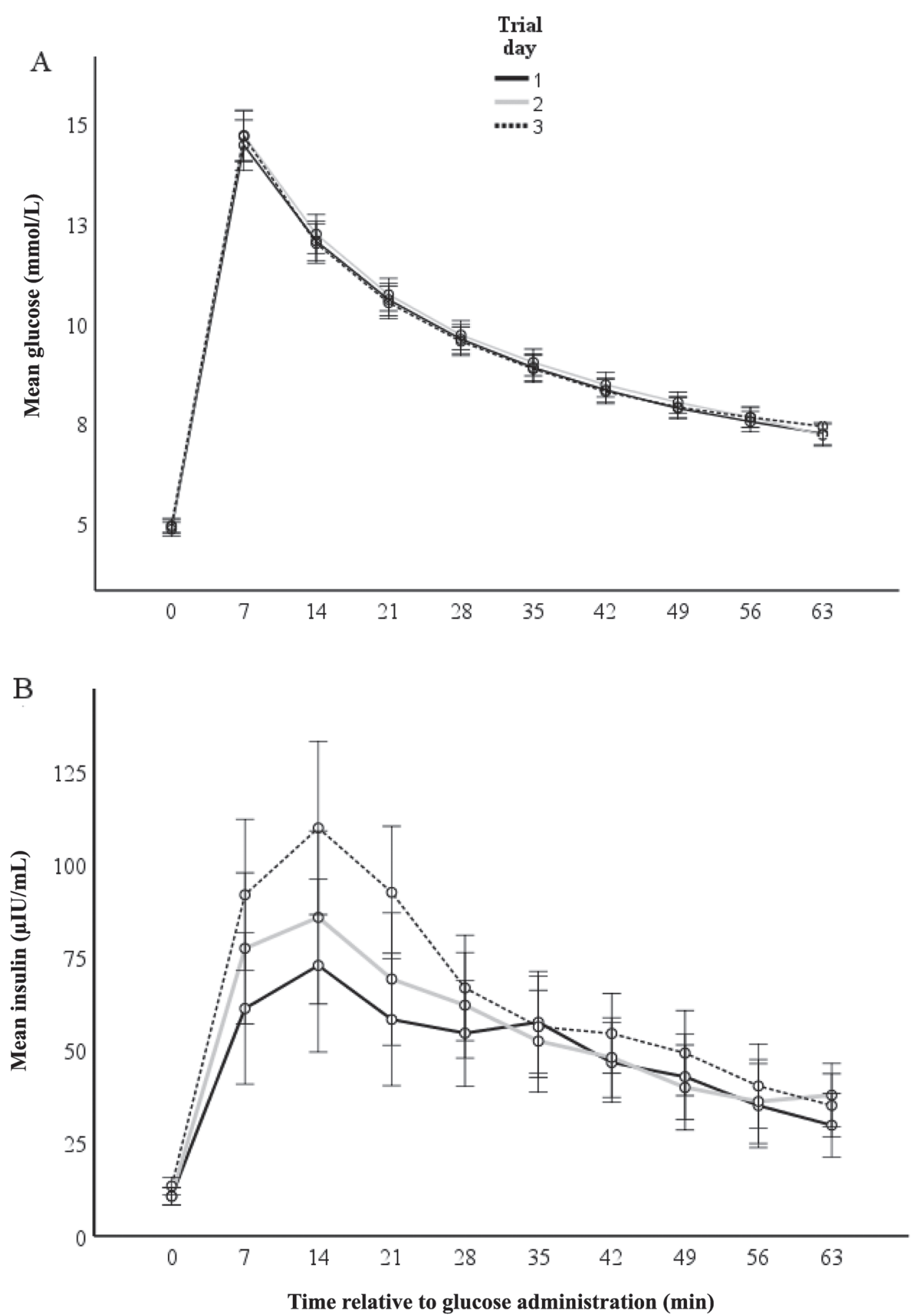

Figure 1. Schematic representation of mean blood serum glucose (A) and insulin (B) concentration at different trial days obtained over $1 \mathrm{~h}$ after glucose injection. Bars indicate SEM. 
fully interpreted in the present study due to the small sample size. Currently, a larger study is investigating these factors (L. A. González-Grajales, L. Pieper, S. Görner, P. Görner, and R. Staufenbiel, unpublished data). However, the influence of sex on glucose metabolism and insulin responses during an ivGTT should be considered when implementing the ivGTT. For instance, decreased basal insulin concentration in heifers was reported when compared with that of bulls (Hayhurst et al., 2009); however, other studies found no statistically significant differences in basal glucose and insulin concentrations between heifers and steers (Walker et al., 2010). Our data on glucose traits and insulin responses demonstrated that glucose traits are highly repeatable under controlled conditions in all tested animals. Contrarily, insulin responses showed high $\mathrm{CV}$ values, which is evidenced by disagreement among measurements and illustrate the complexity of mechanisms governing insulin secretion and disposal rates (Aronoff et al., 2004). In ruminants, insulin is responsible to preserve circulating glucose concentrations within a narrow range, among other functions (Sasaki, 2002). The small variation obtained from all glucose traits at each examination in our study revealed the tight control of blood glucose concentrations exerted by hormones, such as insulin, among other mechanisms (Kaneko, 1997). Glucose tolerance was unaltered over 3 consecutive days with numerical increases in insulin maximal concentration at each trial day. This is the first investigation in young cattle reporting the repeatability of some parameters comprising the ivGTT.

Changes in blood glucose concentrations provoke compensatory or regulatory responses to maintain glucose supply within the normal ranges (Kaneko, 1997). As observed in our study, all glucose traits are highly repeatable with CV for GHLT lower than $1 \%$ in all tested animals. Interestingly, the repeatability for GHLT in horses and cats is not very high with reported CV ranging between 11 to 20\% (Sparkes et al., 1996; Pratt et al., 2005). Thus, the high GHLT repeatability observed in dairy cattle might relate to certain particularities regarding carbohydrate metabolism, such as low peripheral glucose concentrations and limited intestinal glucose absorption (reviewed by De Koster and Opsomer, 2013). As expected, higher individual variability in overall insulin responses was evident for most animals in our study as reported in other species (Sparkes et al., 1996; Pratt et al., 2005). This difference in inter-day repeatability between glucose and insulin concentrations reflects the role of insulin as a regulatory hormone and glucose as a highly regulated metabolite (Kaneko, 1997). Although no significant differences in insulin concentrations over time at any of the trial days were found, numerical increases in insulin maximal concentrations were observed at each day. In healthy humans, when using 2 sequential glucose doses over a 6 -h time period, improvement of glucose tolerance as a result of increased plasma insulin response has been reported (Bonuccelli et al., 2009). Further studies including a larger sample size are necessary to elucidate whether sequential ivGTT lead to increased insulin secretion and the mechanisms controlling it in dairy cattle. Despite the controlled nutritional and housing measures applied in our study, inter-day variation in insulin-mediated glucose uptake, identification of stressors before test implementation, and influence of environmental factors were not assessed in this study. Consequently, to obtain reliable and repeatable data, further studies assessing these variables in dairy cattle are necessary. Among all glucose traits analyzed in this study, GHLT values had the highest repeatability in young dairy cattle, which illustrates the importance of glucose disposal rates to maintain euglycemia.

\section{ACKNOWLEDGMENTS}

We thank Horst Hilmert and Michaela Waberowski, members of the Ruminant and Swine Clinic from the Free University of Berlin, for assisting with hormone analyses.

\section{REFERENCES}

Aronoff, S. L., K. Berkowitz, B. Shreiner, and L. Want. 2004. Glucose metabolism and regulation: Beyond insulin and glucagon. Diabetes Spectr. 17:183-190.

Binici, C., S. Plog, O. Kershaw, M. Schmicke, J. H. van der Kolk, and K. E. Müller. 2016. Insulinoma in a 5-year-old Dexter cow. J. Vet. Intern. Med. 30:1402-1406.

Bonuccelli, S., E. Muscelli, A. Gastaldelli, E. Barsotti, B. D. Astiarraga, J. J. Holst. A. Mari, and E. Ferrannini. 2009. Improved tolerance to sequential glucose loading (Staub-Traugott effect): Size and mechanisms. Am. J. Physiol. Endocrinol. Metab. 297:E532E537.

De Koster, J. D., and G. Opsomer. 2013. Insulin resistance in dairy cows. Vet. Clin. North Am. Food Anim. Pract. 29:299-322.

González-Grajales, L. A., L. Pieper, J. Kremer, and R. Staufenbiel. 2017. Influence of food deprivation on intravenous glucose tolerance test traits in Holstein Friesian heifers. J. Dairy Sci. 100:7710 7719 .

González-Grajales, L. A., L. Pieper, S. Mengel, and R. Staufenbiel. 2018. Evaluation of glucose dose on intravenous glucose tolerance test traits in Holstein-Friesian heifers. J. Dairy Sci. 101:774-782.

Görner, P. 2011. Experimentelle Untersuchungen zu fütterungsabhängigen Einflussfaktoren auf die Insulinantwort im Glukosetoleranztest bei Jungbullen, Ochsen und Färsen. [in German with English abstract]. Doctoral dissertation, Ruminant and Swine Clinic, Free University of Berlin, Germany.

Hayhurst, C., A. P. F. Flint, P. Løvendahl, J. A. Woolliams, and M. D. Royal. 2009. Genetic variation of metabolite and hormone concentration in UK Holstein-Friesian calves and the genetic relationship with economically important traits. J. Dairy Sci. 92:4001-4007.

Kaneko, J. J. 1997. Carbohydrate metabolism and its diseases. Pages 45-81 in Clinical Biochemistry of Domestic Animals. 6th ed. J. J. 
Kaneko, W. J. Harvey, and L. M. Bruss, ed. Academic Press, San Diego, CA.

Kremer, J. 2008. Einfluss der Dauer der Nüchternzeit auf das Ergebnis im intravenösen Glukosetoleranztest beim weiblichen Jungrind [in German with English abstract]. Doctoral dissertation, Ruminant and Swine Clinic, Free University of Berlin, Germany.

McNeel, A. K., B. C. Reiter, D. Weigel, J. Osterstock, and F. A. Di Croce. 2017. Validation of genomic predictions for wellness traits in US Holstein cows. J. Dairy Sci. 100:9115-9124.

Opsomer, G., T. Wensing, H. Laevens, M. Coryn, and A. de Kruif. 1999. Insulin resistance: The link between metabolic disorders and cystic ovarian disease in high yielding dairy cows? Anim. Reprod. Sci. 56:211-222.

Pieper, L., R. Staufenbiel, J. Christ, L. Panicke, U. Müller, and G. A. Brockmann. 2016. Heritability of metabolic response to the intravenous glucose tolerance test in German Holstein Friesian bulls. J. Dairy Sci. 99:7240-7246.
Pratt, S. E., R. J. Geor, and L. J. McCutcheon. 2005. Repeatability of 2 methods for assessment of insulin sensitivity and glucose dynamics in horses. J. Vet. Intern. Med. 19:883-888.

Sasaki, S. 2002. Mechanism of insulin action on glucose metabolism in ruminants. Anim. Sci. J. 73:423-433.

Schröder, U. J., and R. Staufenbiel. 2006. Invited review: Methods to determine body fat reserves in the dairy cow with special regard to ultrasonographic measurement of backfat thickness. J. Dairy Sci. 89:1-14.

Sparkes, A. H., D. T. Adams, P. J. Cripps, T. J. Gruffydd-Jones, and M. Burnett. 1996. Inter-and intraindividual variability of the response to intravenous glucose tolerance testing in cats. Am. J. Vet. Res. 57:1294-1298.

Walker, D. K., E. C. Titgemeyer, T. J. Baxa, K. Y. Chung, D. E. Johnson, S. B. Laudert, and B. J. Johnson. 2010. Effects of ractopamine and sex on serum metabolites and skeletal muscle gene expression in finishing steers and heifers. J. Anim. Sci. 88:1349-1357. 